\title{
Is the diarrhoea in ulcerative colitis related to impaired colonic salvage of carbohydrate?
}

\author{
S S C RAO, N W READ, AND C D HOLDSWORTH
}

From the Sub-Department of Human Gastrointestinal Physiology and Nutrition, Royal Hallamshire Hospital, Sheffield

SUMmARY In order to determine whether failure of the colon to salvage carbohydrate could contribute to the diarrhoea of ulcerative colitis we investigated the effect of ingesting a drink containing $20 \mathrm{~g}$ lactulose on stool output and breath hydrogen production in 39 colitic patients subdivided according to their disease extent and activity and in 14 normal volunteers. Each subject took a standard diet for four days and stool output was monitored throughout this period. Administration of lactulose on day three significantly increased stool weight and frequency in patients with both active and quiescent total colitis $(\mathrm{p}<0.01)$, but not in patients with distal colitis or in the volunteers. The basal and peak breath hydrogen responses to ingested lactulose were similar to normal controls in all patient groups but the hydrogen concentration tended to be higher in colitics. The mouth to caecum transit of the lactulose meal was slower in all groups of colitics $(p<0.02)$ when compared with controls. These results suggest that impaired colonic salvage of carbohydrate could contribute to the diarrhoea in patients with total colitis who are ingesting a diet rich in unabsorbed carbohydrate, or who are hypolactasic.

The mechanisms responsible for diarrhoea in ulcerative colitis are multifactorial and are not fully understood. It is currently believed that excessive intestinal secretion,' excessive propulsive motor activity $^{23}$ and impaired absorption of fluid and electrolytes ${ }^{4}$ may each contribute to the diarrhoea of ulcerative colitis. The aim of this study is to investigate whether impairment of the ability of the diseased colon to salvage unabsorbed carbohydrate could also be responsible for diarrhoea in some patients with ulcerative colitis. Between $30-150 \mathrm{~g}$ of unabsorbed carbohydrate is estimated to reach the colon each day. ${ }^{5}$ This is fermented by colonic bacteria to short chain fatty acids, hydrogen and other gases which are then rapidly absorbed together with salt and water. ${ }^{67}$ If fermentation of carbohydrate is impaired, then the unfermented carbohydrate would retain water by virtue of its osmotic activity and be

Address for correspondence: Dr N W Read. Sub-Department of Human Gastrointestinal Physiology and Nutrition. Floor K, Royal Hallamshire Hospital, Glossop Road, Shefficld S10 2JF.

Received for publication 19 February 1987. voided as diarrhoea. ${ }^{x y}$ Failure of colonic salvage of carbohydrate could occur in ulcerative colitis for several possible reasons (a) there may be ineffective absorption and utilisation of short chain fatty acids by the inflamed and ulcerated mucosa, ${ }^{11}$ " (b) excessive propulsive motor activity ${ }^{2.3}$ and secretion' may flush out the bacteria from the colon, (c) mucosal inflammation could reduce the redox potential of the colonic contents rendering them hostile to the anaerobic bacterial species that are responsible for carbohydrate fermentation. ${ }^{412}$

It has been shown previously that normal subjects can salvage an oral load of $20 \mathrm{~g}$ of the unabsorbable disaccharide, lactulose, without getting diarrhoea. ${ }^{1314}$ Thus in this study, we investigated the effect of the same load of lactulose on stool output and breath hydrogen production in patients with ulcerative colitis.

\section{Methods}

SUBJECTS

These were 39 patients ( 15 men, 24 women; median 
age 44 years [range $=22-79$ years]) who had histologically proven ulcerative colitis, and were categorised according to their disease extent and activity. The extent of the disease was assessed by barium enema and those patients with disease involving the whole colon were grouped as total colitis and those with disease extending proximally up to the splenic flexure were grouped as distal colitis. Disease activity was judged by histological appearances and Truelove and Witts criteria. ${ }^{15}$ Patients who were clinically in remission and had sigmoidoscopic and histological appearances of inactive disease were considered to have quiescent colitis.

A full blood count, ESR, urea and electrolytes and liver biochemistry was always checked before the study and no patient with an electrolyte disturbance was studied. Patients taking drugs such as anticholinergic agents, opiates, iron preparations or stool bulking agents were excluded. Patients taking sulphasalazine and oral prednisolone continued their treatment but patients using steroid enemas were requested to discontinue them during the study. No medication was taken on the morning of the study.

For comparison, measurements were carried out on 14 healthy volunteers ( 12 men, two women; median age 30 years [range $=20-44$ years]).

ETHICAL CONSIDERATIONS

All patients and volunteers gave written informed consent for the study, which was approved by the Ethical Committee of the Sheffield Area Health Authority on 6th November, 1984.

STUDY PROTOCOL

All subjects took a standard $8400 \mathrm{KJ}$, lactose free, low residue diet for a period of four days. The diet consisted of buttered white bread and boiled egg for breakfast, a portion of chicken or fish with boiled potato for lunch and meat sandwiches for dinner. Biscuits, tea and coffee were allowed ad libitum but milk and alcohol were prohibited. On day 3 , after an overnight fast, the subjects drank $30 \mathrm{ml}$ Duphalac (Duphar, Weesp, Holland) which contains $20 \mathrm{~g}$ lactulose, $1.8 \mathrm{~g}$ lactose and $3.3 \mathrm{~g}$ galactose. This was diluted to $100 \mathrm{ml}$ in water and ingested with breakfast. Samples $(50 \mathrm{ml})$ of end expiratory air were obtained for hydrogen analysis using a modified Haldane-Priestly tube, before arid at 10 minute intervals after the test meal for seven hours. ${ }^{16}$ Smoking was prohibited after the test meal and no further food or drink was allowed until breath hydrogen measurements had been completed.

Throughout the study period, all subjects were instructed to collect each stool in separate polyethylene bags and label them with time and date.
BREATH HYDROGEN ANAIYSIS

Breath samples were analysed for hydrogen concentration using an exhaled hydrogen monitor (GMI, Renfrew). The results were plotted and from the profiles the values for the breath hydrogen concentration before the test meal, the peak hydrogen response, the cumulative hydrogen recovery, calculated by measuring the area under the breath hydrogen profile (parts per million $\times$ minutes) and mouth to caecum transit time of the lactulose meal were obtained. The mouth to caecum transit time was defined as the time interval between ingestion of the lactulose meal and an increase in breath hydrogen concentration of at least $5 \mathrm{ppm}$, which continued to rise in samples taken over three consecutive ten minute recordings.

STOOL ANALYSIS

Each stool sample was weighed and the consistency was noted. From these data, the mean daily stool weight, mean daily frequency of defecation and the percentage of unformed stools were calculated for the two days before and the two days after ingestion of lactulose.

STATISTICAL ANALYSIS

Differences in the mean stool weight and frequency before and after lactulose ingestion were analysed using Student's paired $t$ test. The change in the proportion of unformed stools was analysed by fitting logit models to the data and the change in deviance was tested using $\chi^{2}$. The differences in the mouth to caecum transit time were analysed using Student's $t$ test.

\section{Results}

MEAN DAILY STOOL WEIGHT

Administration of lactulose significantly increased mean daily stool weight in patients with active and quiescent total colitis but not in patients with distal colitis or in normal subjects (Table 1).

MEAN DAILY STOOL, FREQUENCY

Ingestion of lactulose significantly increased mean daily stool frequency in patients with both active and quiescent total colitis but not in patients with distal colitis nor in normal subjects (Table 1).

STOOL CONSISTENCY

After ingestion of lactulose there was a significant increase in the proportion of stools that were unformed in patients with active and quiescent total colitis and in active distal colitis (Table 1). There were no significant changes in patients with quiescent distal colitis and in normal subjects. 
Table 1 Effect of lactulose on stool output in normal subjects and in patients with ulcerative colitis

\begin{tabular}{|c|c|c|c|c|c|c|c|c|c|}
\hline & \multicolumn{3}{|c|}{ Mean daily stool frequency } & \multicolumn{3}{|c|}{ Mean daily stool weight ( $g$ ) } & \multicolumn{3}{|c|}{$\begin{array}{l}\text { Stool consistency } \\
\text { (\% stools unformed) }\end{array}$} \\
\hline & $\begin{array}{l}\text { Control } \\
\text { period }\end{array}$ & $\begin{array}{l}\text { After } \\
\text { lactulose }\end{array}$ & $p$ & $\begin{array}{l}\text { Control } \\
\text { period }\end{array}$ & $\begin{array}{l}\text { After } \\
\text { lactulose }\end{array}$ & $p$ & $\begin{array}{l}\text { Control } \\
\text { period }\end{array}$ & $\begin{array}{l}\text { After } \\
\text { lacutlose }\end{array}$ & $p$ \\
\hline Normal subjects $(n=14)$ & $1 \cdot 4 \pm 1$ & $1 \cdot 5 \pm 0 \cdot 5$ & NS & $180 \pm 112$ & $190 \pm 110$ & NS & 8 & 18 & NS \\
\hline \multicolumn{10}{|c|}{ Patients with ulcerative colitis } \\
\hline Active distal $(n=11)$ & $2 \cdot 3 \pm 1 \cdot 2$ & $2 \cdot 5 \pm 2 \cdot 1$ & NS & $160 \pm 106$ & $168 \pm 153$ & NS & 58 & 82 & $<0 \cdot 01$ \\
\hline Quiescent distal $(n=11)$ & $1 \cdot 0 \pm 0 \cdot 6$ & $1 \cdot 1 \pm 0 \cdot 5$ & NS & $103 \pm 47$ & $107 \pm 39$ & NS & 15 & 28 & NS \\
\hline Active total $(n=9)$ & $3 \cdot 3 \pm 1 \cdot 2$ & $4 \cdot 9 \pm 1 \cdot 3$ & $<0 \cdot() 1$ & $247 \pm 119$ & $350 \pm 129$ & $<0 \cdot 01$ & 76 & 97 & $<0 \cdot 001$ \\
\hline Quiescent total $(n=8)$ & $1 \cdot 8 \pm 1 \cdot 3$ & $2 \cdot 2 \pm 1 \cdot 7$ & $<0 \cdot 05$ & $120 \pm 78$ & $190 \pm 110$ & $<0 \cdot 01$ & 16 & 56 & $<0 \cdot 001$ \\
\hline
\end{tabular}

Results are expressed as mean $\pm \mathrm{SD}$.

BREATH HYDROGEN MEASUREMENTS

Examples of typical breath hydrogen profiles are shown in the Figure. The mean basal and peak hydrogen responses to the lactulose meal were similar in colitic patients and normal controls (Table $2)$. The breath hydrogen concentration returned to preprandial levels within seven hours in $12 / 14$ normal subjects but in only $6 / 39$ patients with ulcerative colitis. Although the average area under the curve for the hydrogen response in patients with ulcerative colitis was not significantly different from that found in normal subjects (Table 2), the observation that the hydrogen values (a) tended to be higher and (b) the concentration had not returned to baseline by the time the measurements ceased, suggested that the colitics were probably producing more hydrogen.

\section{MOUTH TO CAECUM TRANSIT TIME}

The mouth to caecum transit of the lactulose drink was significantly slower $(p<0.02)$ in all groups of patients with colitis when compared with normal volunteers (Table 2) but there were no differences between the patient groups.

\section{Discussion}

Ingestion of $20 \mathrm{~g}$ lactulose by normal subjects did not result in any increase in stool output, supporting the previous conclusions of Saunders and Wiggins. ${ }^{13}$ Patients with distal colitis also showed no change in stool output after lactulose ingestion, suggesting that their colons, like those of normal subjects, were able to salvage the additional load of unabsorbable carbohydrate.

In patients with total colitis, on the other hand, ingestion of lactulose produced a significant increase in stool weight and frequency together with a higher proportion of unformed stools. These effects of lactulose appeared to be independent of the activity of the disease. As the diet was strictly controlled during the study, the increased stool output must represent a failure of the colon of patients with total colitis to salvage the extra load of unabsorbed carbohydrate. As most carbohydrate fermentation and absorption is thought to take place in the proximal colon, ${ }^{617}$ one might expect that only those patients with proximal disease would be unable to deal with a carbohydrate challenge.

The failure of patients with total colitis to salvage $20 \mathrm{~g}$ lactulose could be caused by reduced fermentation of carbohydrate as well as impaired absorption or utilisation of short chain fatty acids. The observation that the hydrogen response to lactulose tended to be higher in colitics suggests that fermentation is if anything better than normal. Although we did not measure concentration of short chain fatty acids, it

Table 2 Analysis of the breath hydrogen profile induced by lactulose in normal subjects and in patients with ulcerative colitis

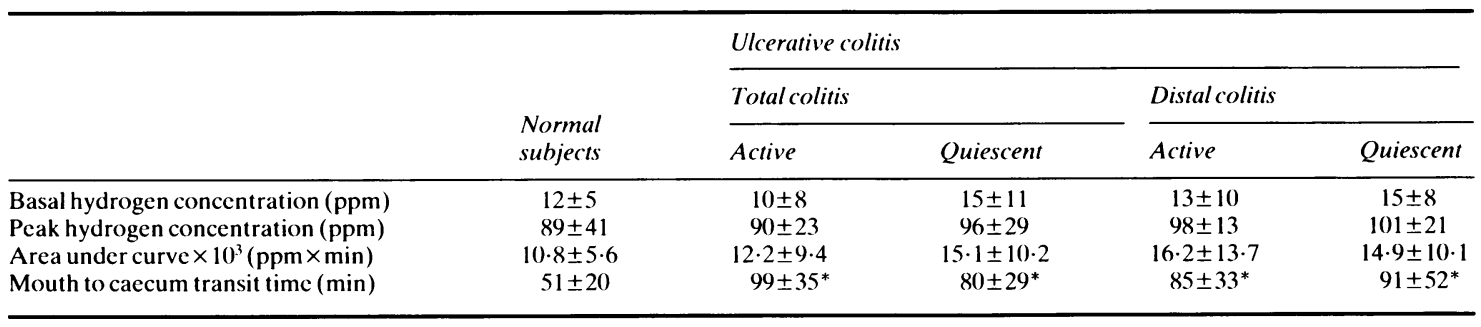

Results are expressed as mean $\pm \mathrm{SD} ;{ }^{*}$ significantly different from normals $\mathrm{p}<0 \cdot(02$. 


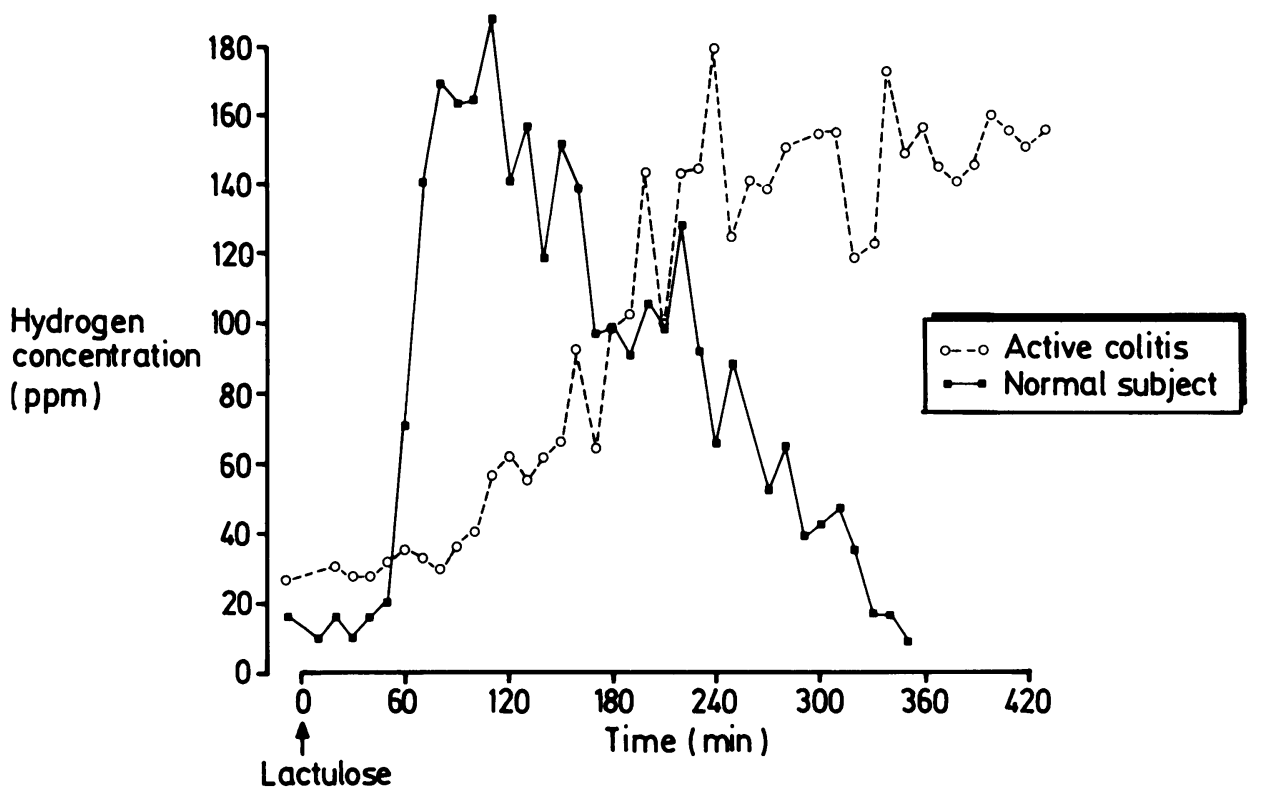

Figure Typical breath hydrogen profiles induced by a drink of lactulose in a normal subject and in a patient with ulcerative colitis.

has been shown that after lactulose ingestion there is a good correlation between breath hydrogen and blood acetate levels. ${ }^{\text {ix }}$ Thus our data are more compatible with impaired colonic utilisation of the products of fermentation. This is supported by the previous observations that patients with ulcerative colitis have high concentrations of short chain fatty acid in the colonic lumen" and excrete larger amounts of short chain fatty acids in the stool."'

There was no evidence to support the concept that the increased rate of delivery of lactulose from the small intestine could have impaired colonic salvage by overloading or flushing out the proximal colon..$^{19210}$ Mouth to caecum transit time was slower in patients with colitis, confirming results of previous studies 212 and suggesting that if anything, lactulose leaves the ileum more slowly than in normal subjects. Proximal colonic transit has also been shown to be delayed in patients with active colitis." ${ }^{21}$ Thus, the impaired salvage of carbohydrate is not caused by abnormally propulsive motor activity in the proximal colon. Instead the proximal colonic stasis would favour an increased breakdown of carbohydrate and could explain the tendency to a greater breath hydrogen excretion in colitics. A greater gas production could in turn explain why patients with active colitis often complain of excessive flatulence..$^{23}$

Our results show that patients with total colitis are able to accommodate a lesser amount of lactulose in the colon than normal subjects. The data provide a good model for the handling of dietary lactose by colitics. One pint of milk contains $25 \mathrm{~g}$ lactose and if a colitic has hypolactasia he would be unlikely to salvage this amount. Hypolactasia is prevalent in about $20 \%$ of normal adult Western population ${ }^{24}$ and this prevalence is apparently no higher in colitics, ${ }^{.5}$ although some workers have reported a higher incidence. ${ }^{26}{ }^{27}$ Inability of the diseased colon to salvage lactose could explain the association between ingestion of milk and diarrhoea in some patients with ulcerative colitis. ${ }^{2023}$ Our findings may also be relevant to the salvage of other complex polysaccharides as suggested by studies which showed that withdrawal of carbohydrate from the diet led to a reduction in stool output in patients with severe colitis. "11310

We would not suggest that impaired salvage of carbohydrate plays a major pathophysiological role in the production of diarrhoea in patients with ulcerative colitis. It is likely that colonic inflammation with hypersecretion' and distal colonic irritability ${ }^{23131}$ are more important in most patients. Impaired colonic salvage of carbohydrates is, however, a factor to be considered in patients ingesting a diet rich in unabsorbed carbohydrate. In such patients this mechanism would explain persistent diarrhoea despite endoscopic remission.

Dr S S C Rao is supported by a grant from the Special Trustees of the Former United Sheffield Hospitals. 
The authors are grateful to Dr R A Dixon and Mr Jon Nicholl for their help with statistical analysis and to Mrs Josie Wilson for her expert secretarial help.

\section{References}

1 Archampong EQ, Harris J, Clark CG. The absorption and secretion of water and electrolytes across the healthy and the diseased human colonic mucosa measured in vitro. Gut 1972; 13: 88()-6.

2 Spriggs EA, Code CF, Bargen JA, Curtiss RK. Hightower NC. Motility of the pelvic colon and rectum of normal persons and patients with ulcerative colitis. Gastroenterology 1951; 9: 480-91.

3 Chaudhary NA, Truelove SC. Human colonic motility: a comparative study of normal subjects, patients with ulcerative colitis and patients with irritable bowel syndrome. I. Resting patterns of motility. Gastroenterology 1961; 40: 1-17.

4 Kerlin P, Phillips SF. Absorption of fluids and electrolytes from the colon: with reference to inflammatory bowel disease. In: Allan RN, Keighley MRB, Alexander-Williams J, Hawkins C, eds. Inflammatory bowel disease. Edinburgh: Churchill Livingstone, 1983: 47-53.

5 Cummings $\mathrm{JH}$. Colonic absorption: the importance of short chain fatty acids in man. Scand $J$ Gastroenterol 1984; 19: 89-99.

6 Ruppin H, Bain-Meir S, Soergel KH, Wood CM, Schmitt MG. Absorption of short chain fatty acids by the colon. Gastroenterology 1980; 78: 1500-7.

7 Dawson AM, Holdsworth CD, Webb J. Absorption of short chain fatty acids in man. Proc Soc Exp Biol Med 1964; 117: 97-100.

8 Caspary WF, Lembcke B, Elsenhans B. Bacterial fermentation of carbohydrate within the gastrointestinal tract. Clin Res Rev 1981; 1: 107-17.

9 Read NW. Diarrhoea. The failure of colonic salvage. Lancet 1982; ii: 481-3.

10 Montgomery RD, Frazer AC, Hood C, Goodhart JM, Holland MR, Schneider R. Studies of intestinal fermentation in ulcerative colitis. Gut 1968; 9: 521-6.

11 Roediger WEW, Heyworth M, Willoughby P, Piris J, Moore A, Truelove SC. Luminal ions and short chain fatty acids as markers of functional activity of the mucosa in ulcerative colitis. J Clin Pathol 1982; 35: 323-6.

12 Read NW, Johnson AJ. Disturbances of intestinal motor activity. In: Allan RN, Keighley MRB, Alexander-Williams J, Hawkins C, eds. Inflammatory bowel diseases. Edinburgh: Churchill Livingstone, 1983: 54-7.

13 Saunders PR, Wiggins HS. Conservation of mannitol, lactulose and raffinose by the human colon. $A m J$ Physiol 1981; 241: G397-G402.

14 Rao SSC, Edwards CA, Austen CJ, Beattie VA, Read
NW, Holdsworth CD. Effect of ampicillin on the colonic salvage of carbohydrate [Abstract]. Gut 1985; 26: A1152.

15 Truelove SC, Witts LJ. Cortisone in ulcerative colitis. Final report on a therapeutic trial. $\mathrm{Br} \operatorname{Med} J$ 1955; 2: 1041-8.

16 Read NW, Al-Janabi MN, Bates TE, Cann PA, Kinsman RI, McFarlane A. The interpretation of the breath hydrogen profile after ingesting a solid meal containing unabsorbable carbohydrate. Gut 1985; 26: 834-42.

17 Bond JH, Currier BE, Buchwald H, Levitt MD. Colonic conservation of malabsorbed carbohydrate. (Fastroenterology 1980; 3: 444-7.

18 Pomare EW, Branch WJ, Cummings JH. Carbohydrate fermentation in the human colon and its relation to acetate concentrations in venous blood. J Clin Invest 1985; 75: 1448-54.

19 Chauve A, Devroede G, Bastin E. Intraluminal pressures during perfusion of the human colon in situ. Gastroenterology 1976; 70: 336-40.

20) Palma R, Vidon N, Bernier JJ. Maximal capacity for fluid absorption in human bowel. Dig Dis Sci 1981; 26: 929-34.

21 Rao SSC, Read NW. Holdsworth CD. Gastrointestinal transit and stool output in the pathophysiology of diarrhoea in ulcerative colitis. Clin Sci 1986; 71: 41 .

22 Manousos ON, Salem SN. Abnormal motility of the small intestine in ulcerative colitis. Gastroenterologia 1965; 104: 249-57.

23 Hurst AF. Ulcerative colitis. Guy Hosp Rep 1921; 71: $26-41$.

24 Kretchmer $N$. The geography and biology of lactose digestion and malabsorption. In: Barltrop D, ed. Paediatric implications for some adult disorders. Scientific Proceedings of the Fourth Unigate Paediatric Workshop. Fellowship of Postgraduate Medicine, London. Postgrad Med J 1977; 53: 65-72.

25 Newcomer AD, McGill DB. Incidence of lactase deficiency in ulcerative colitis. Gastroenterology 1967; 53: 890-3.

26 Binder HJ, Gryboski JD, Thayer WR Jr, Spiro HM. Intolerance to milk in ulcerative colitis: a preliminary report. Am J Dig Dis 1966; 11: 858-64.

27 Cady AB, Rhodes J, Littman A. Crane RA. Significance of lactase deficit in ulcerative colitis. $J$ Lab Clin Med 1967; 70: 279-86.

28 Truelove SC. Ulcerative colitis provoked by milk. $\mathrm{Br}$ Med J 1961; 1: 1.54-6).

29 Wright R. Truelove SC. A controlled therapeutic trial of various diets in ulcerative colitis. $\mathrm{Br}$ Med $J$ 1965; 2: 142-4.

30) Frazer AC. Hood C. Montgomery RD, Davies AG, Schneider R. Carter PA, Goodhart J. Carbohydrate intolerance in ulcerative colitis. Lancet 1966; i: 503-5.

31 Farthing MJG, Lennard-Jones JE. Sensitivity of the rectum to distension and the anorectal distension reflex in ulcerative colitis. Gut 1978; 19: 64-9. 